\title{
Optical and Morphological Properties of (PVA-PVP-Ag) Nanocomposites
}

\author{
Zainab A. Al-Ramadhan ${ }^{1}$, Jehan A. Salman², Hamsa Abdul Karem Hmud ${ }^{3}$ \\ ${ }^{1,2,3}$ AL-Mustansiriyah University, College of Education, Department of Physics, Iraq
}

\begin{abstract}
Polymer-nanocomposite were prepared by solution cast method using Co-Polymer(Polyvinyl alcohol and Polyvinyl pyrrolidone) as matrix and silver nanoparticle as filler. Optical properties of (PVA-PVP-Ag) nanocomposite with different percentage $(0,1,2,3,4,5) w t \%$ and thickness $120 \mu \mathrm{m}$ were investigated using UV-VS spectrocopy within spectral region (200-900)nm. The energy gap of indirect transition (allowed and forbidden) has been determined, and their values were decrease with increasing nanoparticles concentration. The dispersion phenomena for refractive index and extinction coefficient are also investigated, the refractive index increase with the increasing of Ag content. The morphology analysis of the samples are determind by AFM measurements and optical microscope. The result show homogeneous distribution, very smooth surface and small roughness.
\end{abstract}

Keywords: Polymer, nanocomposite, optical properties, nanoparticles

\section{Introduction}

In recent years, a noble metal nanoparticles such as nano silver is of great significant due to size dependent optical properties [1]. These special and unique properties could be attributed to their small sizes and large specific surface area. The metallic nanoparticles have been used in many applications such as catalysis, electronics and photonics. Polymers are considered to be an excellent host material for nanoparticles of metals [2]. The polymer will acts as surface capping agent when the nanoparticles are embedded into them. The obtained nanocomposites might exhibit enhanced optical properties [3]. However, the properties of polymer composites depend on type of incorporated nanoparticles, as well as their size and shape, concentration and interaction with the polymer matrix.

\section{Experimental Materials}

The materials used in this work are commercial: Polyvinyl alcohol (PVA), it was obtained as a fine powder Shanghai Kaidu Industrial Development Co., Ltd China , the origin of PVP is Anhui LeafchemCo., Ltd, and Silver nano powder Black Color size(20nm) with a purity(99.99\%) supplied from(Hongwu nanometer).
Films were prepared by weight percent $(0,1,2,3,4$ and 5 wt\%). It was dissolved in distilled water using magnetic stirrer about $(1 \mathrm{hr})$. The process of sonicacation is one that shoots ultrasonic waves at the sample; therefore aiding dispersion of the filler and creating a more homogenous solution ,then to prepare the films, each sample is poured in $5 \times 5 \mathrm{~cm}^{2}$ glass basin after being cleaned with water and acetone. They placed on a flat table surface. The thickness of the dried samples is about $(120 \mu \mathrm{m})$.

\section{Results and Discussion}

\section{1- Optical properties}

The UV-VIS absorbance spectra in the region 200-900nm for PVA-PVP-Ag nanocomposites are shown in Figure (1). It is clear from the figure that the absorption spectra for all films decreased with increasing wavelength, while the absorption increased with increasing concentration of Ag. This is because silver nanoparticles ions are combined with the polymer chains which absorb the incident radiation at the shortest wavelengths greater than $250 \mathrm{~nm}$ by the free electrons $[4,5]$.

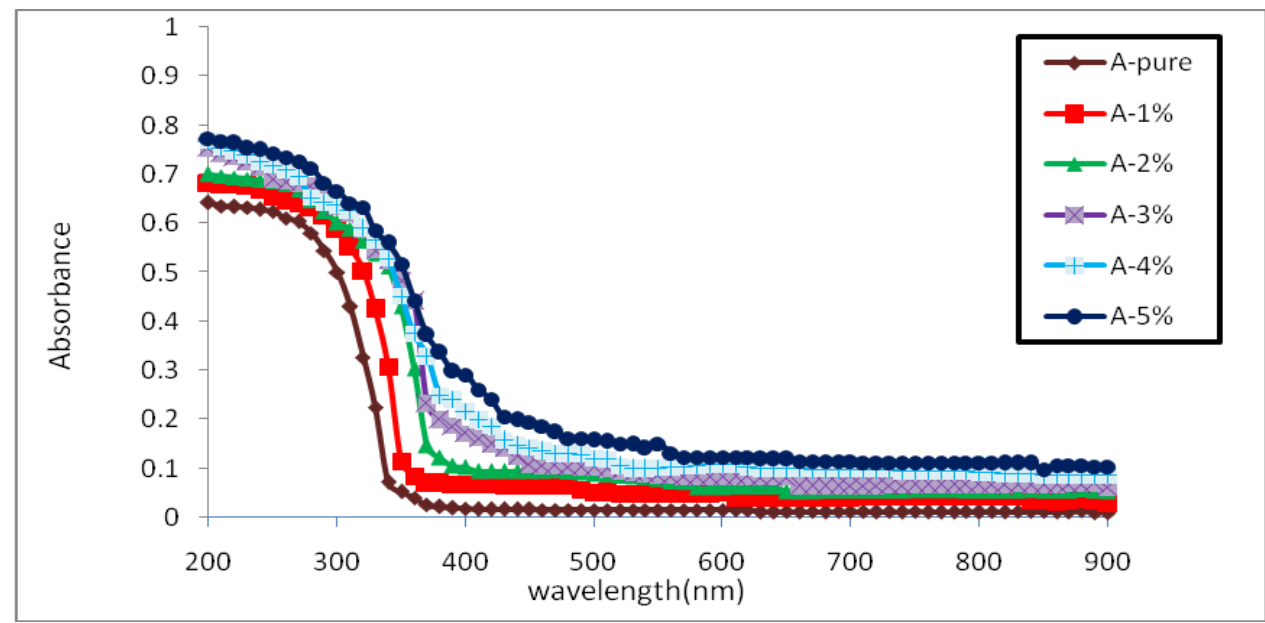

Figure 1: The absorbance for (PVA-PVP-Ag) nanocomposits as a function of wavelength. 


\section{International Journal of Science and Research (IJSR) \\ ISSN (Online): 2319-7064 \\ Index Copernicus Value (2013): 6.14 | Impact Factor (2014): 5.611}

The optical transmission spectra of the (PVA-PVP) films with different concentrations of nano Ag are shown in Figure (2). This figure shows that the transmittance intensity increases with the increasing of the wavelength, and as the concentration of nano Ag increases, the transmittance decreases. This behavior is because of the form of covalent bonds between polymer chains and additives that decrease the transmitting of the incident light especially at the shortest wavelengths. The electrons in the outer orbits have travelled to the higher energy levels and have occupied vacant positions of energy bands. Thus, part of incident light does not penetrate through it [6].

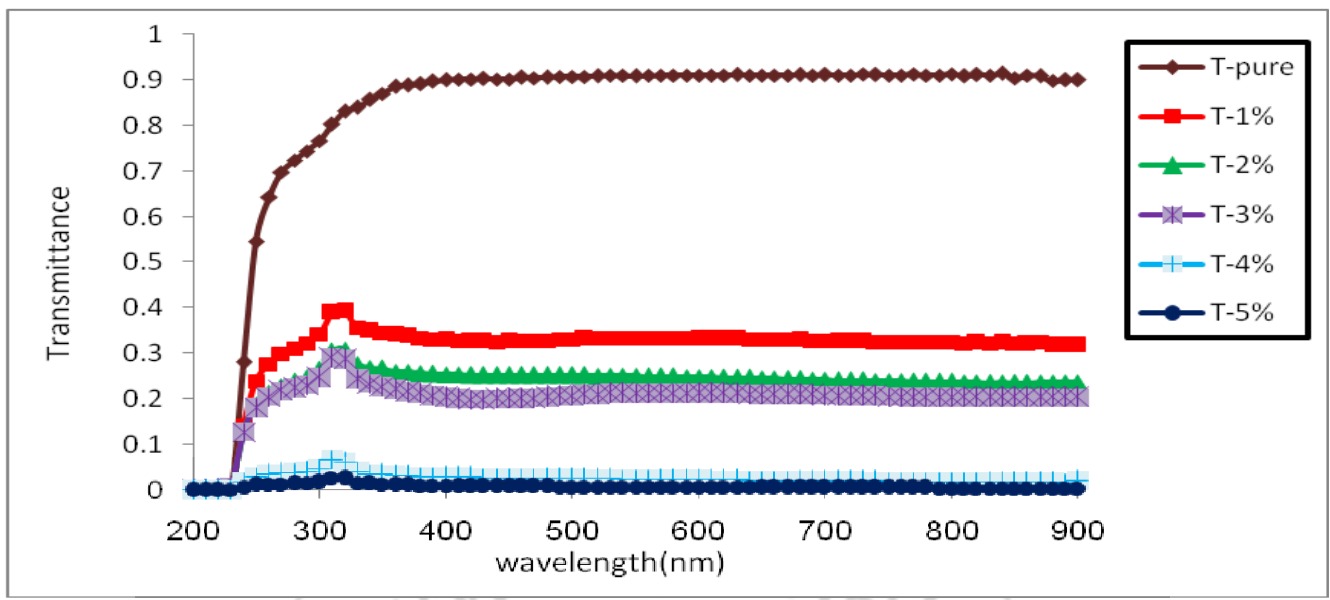

Figure 2: The transmittance for (PVA-PVP-Ag) nanocomposits as a function of wavelength

The absorption coefficient $\alpha(\mathrm{cm})^{-1}$ is calculated by using equation (1).

$$
\alpha=2.303(\mathrm{~A} / \mathrm{t})
$$

where (A) is the absorbance and ( $t)$ is the thickness of films

Figure (3) shows the absorption coefficient $\alpha(\mathrm{cm})^{-1}$ as a function of wavelength At low energies(high wave length), the possibility of electron transition is little, because the energy is not sufficient to move this electron from the valence band to the conduction band (hv < Eg) [4]. At high energies(low wave length), absorption is great, this means that a great possibility for electron transitions consequently, the energy of incident photon is enough to move the electron from the valence band to the conduction band , the energy of the incident photon is greater than the energy gap[6]. This shows that the absorption coefficient assists in figuring out the nature of electron transition, [7] ,among other results the coefficient of absorption for the (PVA-PVP-Ag) composites is less than $10^{4} \mathrm{~cm}^{-1}$ this means transitions is indirect.

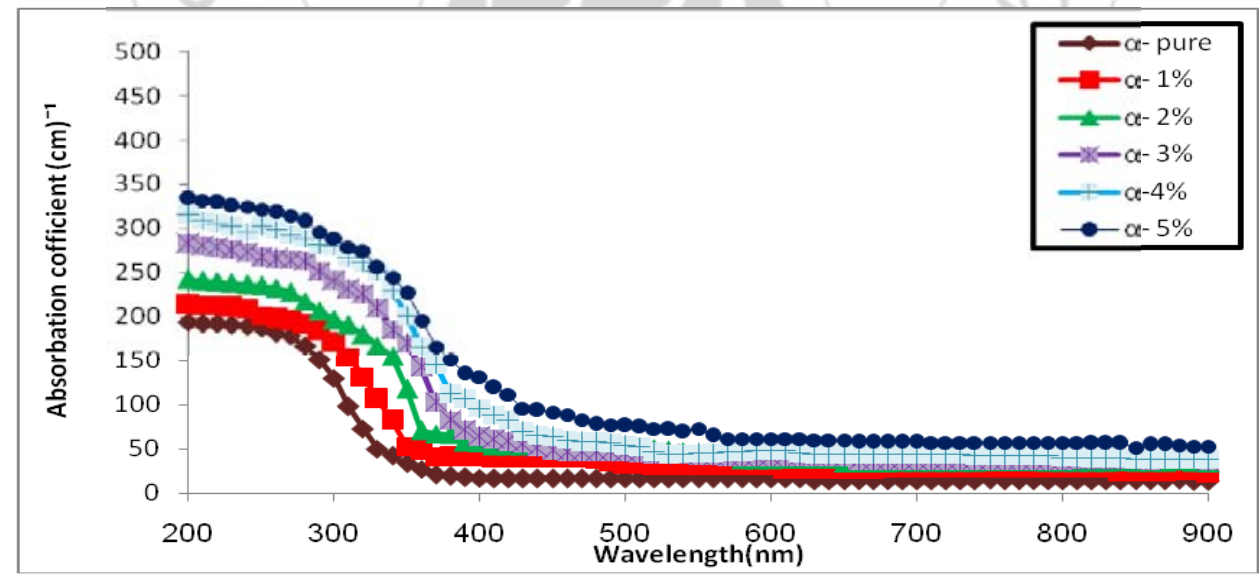

Figure 3: The absorption coefficient for (PVA-PVP-Ag) nanocomposites as a function of wavelength

Refractive index (n) was determined from the absolute values of the absorbance and transmittance of the investigated films using the following equation (2):

$$
n=\sqrt{\frac{4 R-k^{2}}{(R-1)^{2}}}-\frac{(R+1)}{(R-1)}
$$

where $\mathrm{R}$ is the optical reflectance. The relationship of the reflectance and the wavelength of the incident light for the
(PVA-PVP-Ag) composites with various filler contents is shown in figure (4) .It is clear that there is change in the position of the peak for all amounts of adding the nano particals to the pure polymer, and this result means that there is change in the polymer structure in the value of $\mathrm{E}_{\mathrm{g}}$ [8]. 


\section{International Journal of Science and Research (IJSR) \\ ISSN (Online): 2319-7064}

Index Copernicus Value (2013): 6.14 | Impact Factor (2014): 5.611

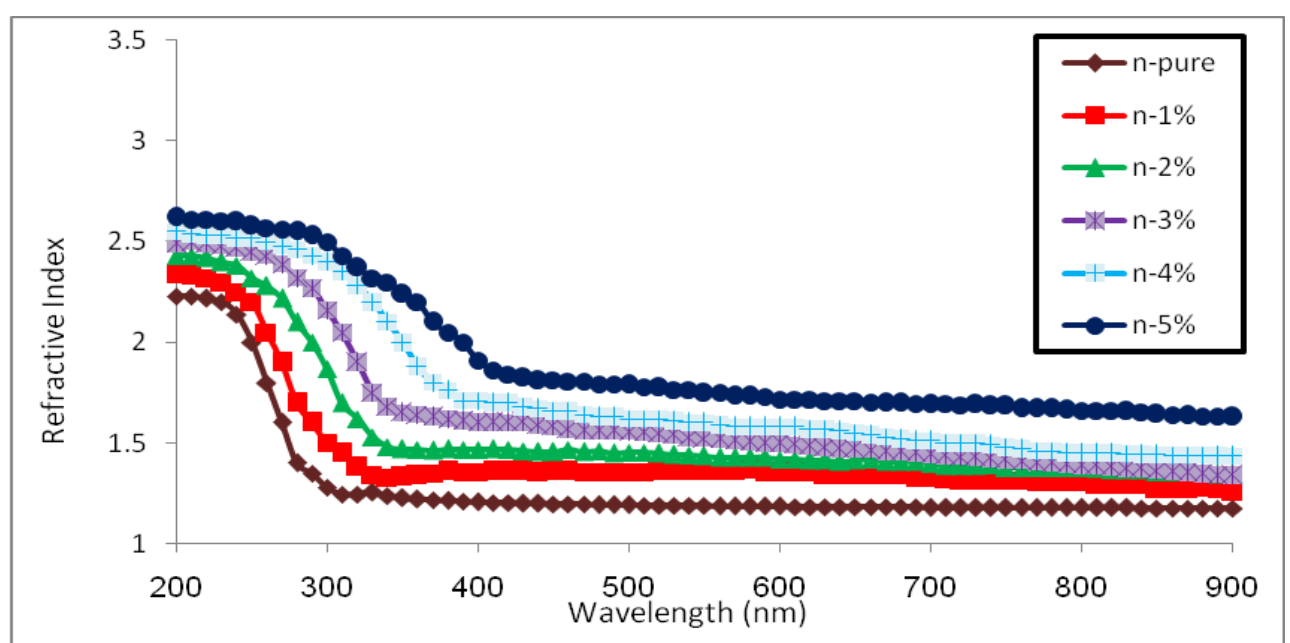

Figure 4: The reflactive index for (PVA-PVP-Ag)nanocomposite as a function of wavelength

The extinction coefficient was determined using the In Figure (5), The relationship between the extinction following equation (3).

$$
k=\frac{\alpha \lambda}{4 \pi}
$$

where $\alpha$ is the absorption coefficient and $(\lambda)$ is the wavelength of incident ray. coefficient and wavelength of the composites are shown in figure (5). The extinction coefficient increases with increasing of (Ag) concentration, this may be attributed to high absorption coefficient. This result indicates that Ag atoms will modify the structure of the host polymer. An interesting result is silver nanoparticles increases the absorbance in the visible region [9].

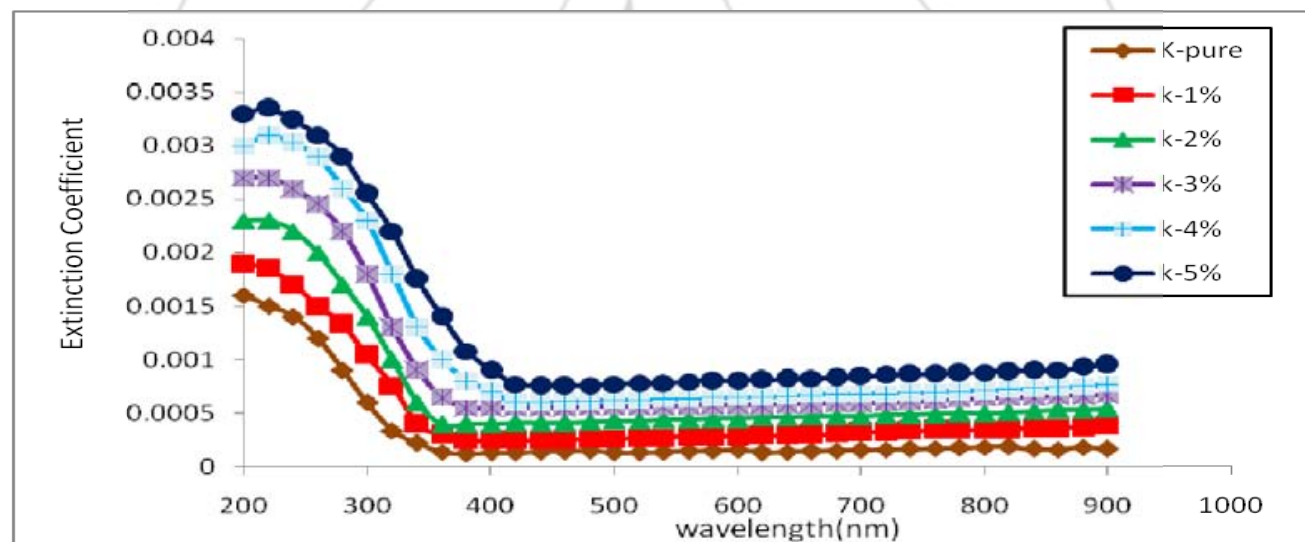

Figure 5: The Extinction cofficicient for (PVA-PVP-Ag) nanocomposite as a function of incident wavelength

The dependence of the real part of dielectric constant $\varepsilon_{1}$ is shown in Figure (6) for pure sample and with Ag nanoparticles. The real part are increase with increasing wavelength and Ag concentration, moving the curves vertex to higher wavelengths were happened with increasing Ag nanoparticles percentage may be attributed to related real part of dielectric constant with refractive index by equation (4) [10].

$$
\begin{gathered}
\varepsilon_{1}=\mathrm{n}^{2}-\mathrm{k}^{2} \\
\varepsilon_{2}=2 \mathrm{nk}
\end{gathered}
$$

where, $\left(\varepsilon_{1}, \varepsilon_{2}\right)$ are the real and imaginary parts of the dielectric constant, respectively. 


\section{International Journal of Science and Research (IJSR) \\ ISSN (Online): 2319-7064}

Index Copernicus Value (2013): 6.14 | Impact Factor (2014): 5.611

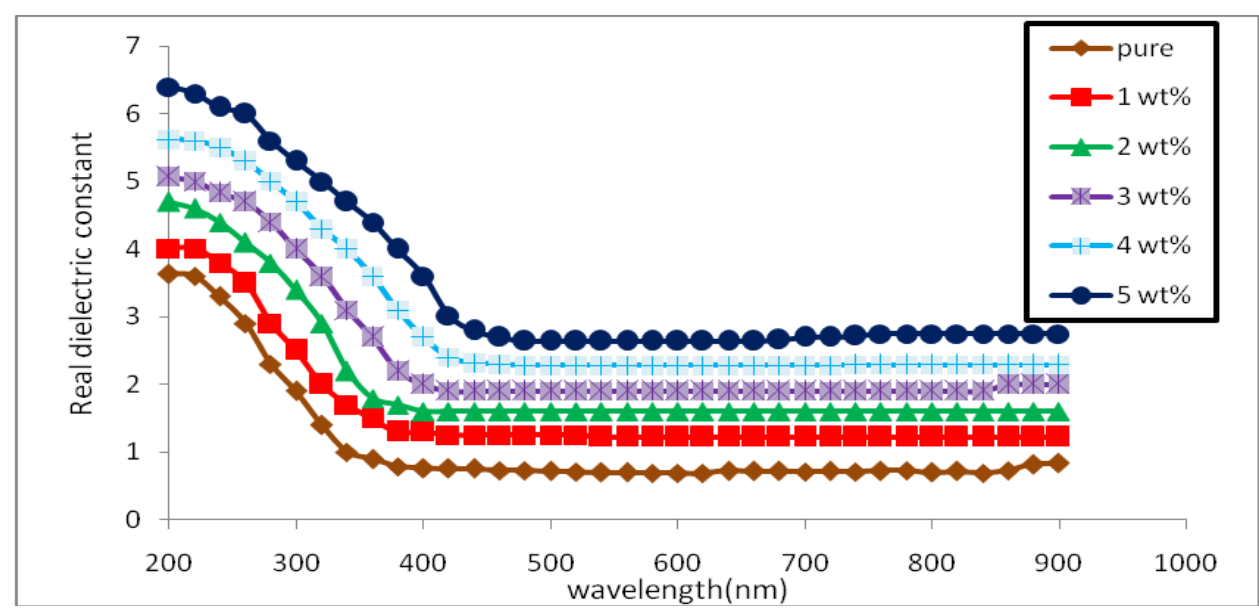

Figure 6: The real dielectric constant for (PVA-PVP-Ag) nanocomposite as a function of wavelength

The imaginary part of dielectric constant as a function of wavelength is shown in Figure (7). It is clear that the imaginary part depends on extinction coefficient by equation(5) because the refractive index is very small [11]. appear which indicate that the samples have no same structure. Hence, the change in the percentage of Ag gave change in the chemical composition of the polymer. The absorption spectra clarify an extending tail for lower photon energies below the band edge, [12].

The imaginary part increases for all wavelengths $200 \mathrm{~nm}$ to $900 \mathrm{~nm}$ and with increasing Ag percentage. New peaks

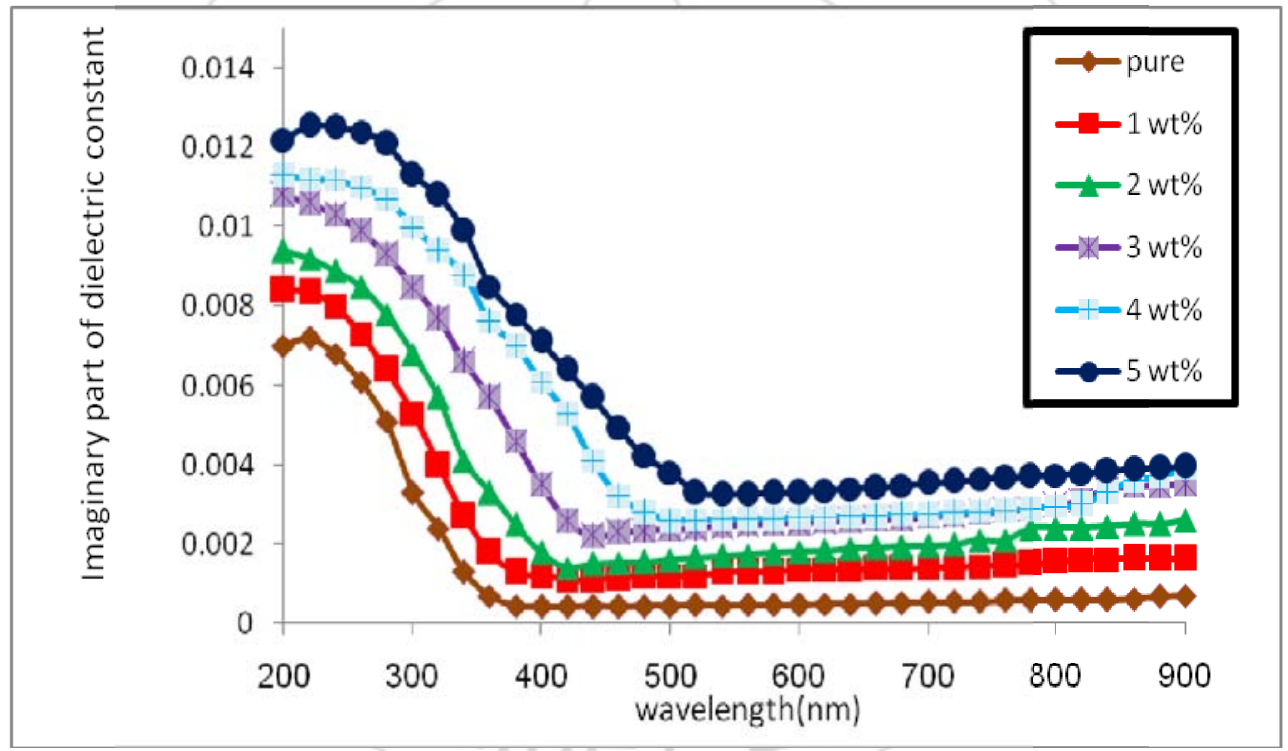

Figure 7: The imaginary dielectric constant for (PVA-PVP-Ag) nanocomposits as a function of wavelength

Figure (8) shows the relation between $(\alpha h v)^{1 / 2}$ for (PVAPVP-Ag) nanocomposites as a function of photon energy to drawing a straight line from the upper part of the curve toward the (uv) axis. at the value $(\alpha h v)^{1 / 2}=0$ we get energy gap for the allowed indirect transition .The obtained values are shown in table (1). We can see that the values of energy gap decrease with the increasing of the weight percentage of the added nano particles, this attributed to the creation of onsite levels in the energy gap ,the transition in this case is involve the transition of electron from the valence band to the local levels as a result of increasing Ag percentage. This behavior is attributed to the fact that composites are of heterogeneous type (i.e.the electronic conduction depends on added Ag nanoparticles), the increase of the added rate provides electronic paths in the polymer which facilitate the crossing of electron from the valance band to the conduction band ,this explains the decrease of energy gap with the increase of the concentration of the additive [13] .The forbidden transition of the indirect energy gap is calculated in the same way.

Figure (9) shows the forbidden transition of the indirect energy gap for the (PVA-PVP-Ag) nanocomposites.

Table 1: The values of energy gap for the allowed and indirect forbidden transition

\begin{tabular}{|c|c|c|}
\hline Silver nanoparticles (wt.\%) & \multicolumn{2}{|c|}{$\mathrm{Eg}(\mathrm{eV})$} \\
\cline { 2 - 3 } & allowed & forbidden \\
\hline 0 & 4.8 & 4.7 \\
\hline 1 & 4.6 & 4.5 \\
\hline 2 & 4.4 & 4.25 \\
\hline 3 & 4.2 & 4.16 \\
\hline 4 & 4.1 & 4 \\
\hline 5 & 3.92 & 3.8 \\
\hline
\end{tabular}


International Journal of Science and Research (IJSR)

ISSN (Online): 2319-7064

Index Copernicus Value (2013): 6.14 | Impact Factor (2014): 5.611
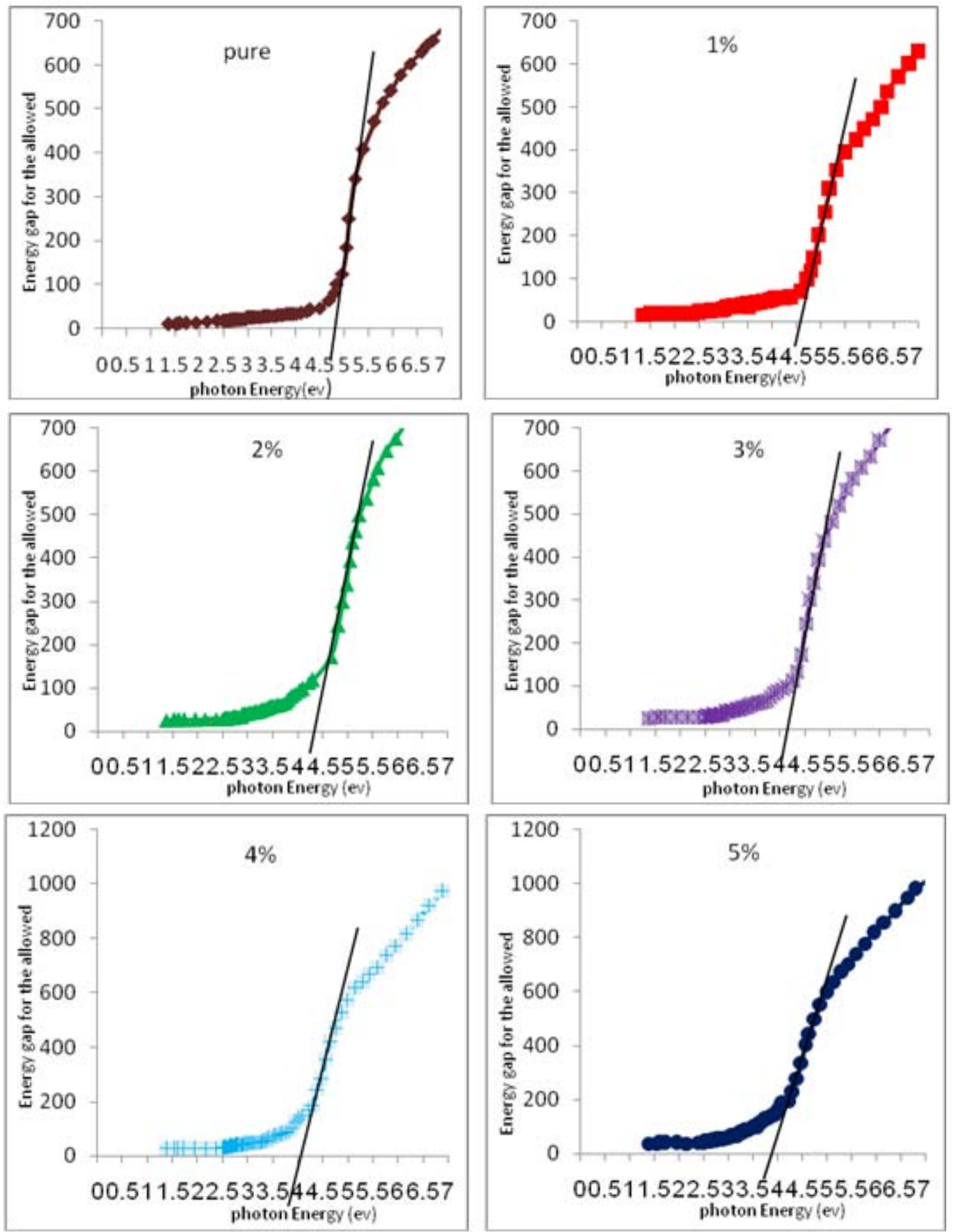

Figure 8: The energy gap for the allowed indirect transition as a function of photon energy of (PVA-PVP-Ag) nanocomposites
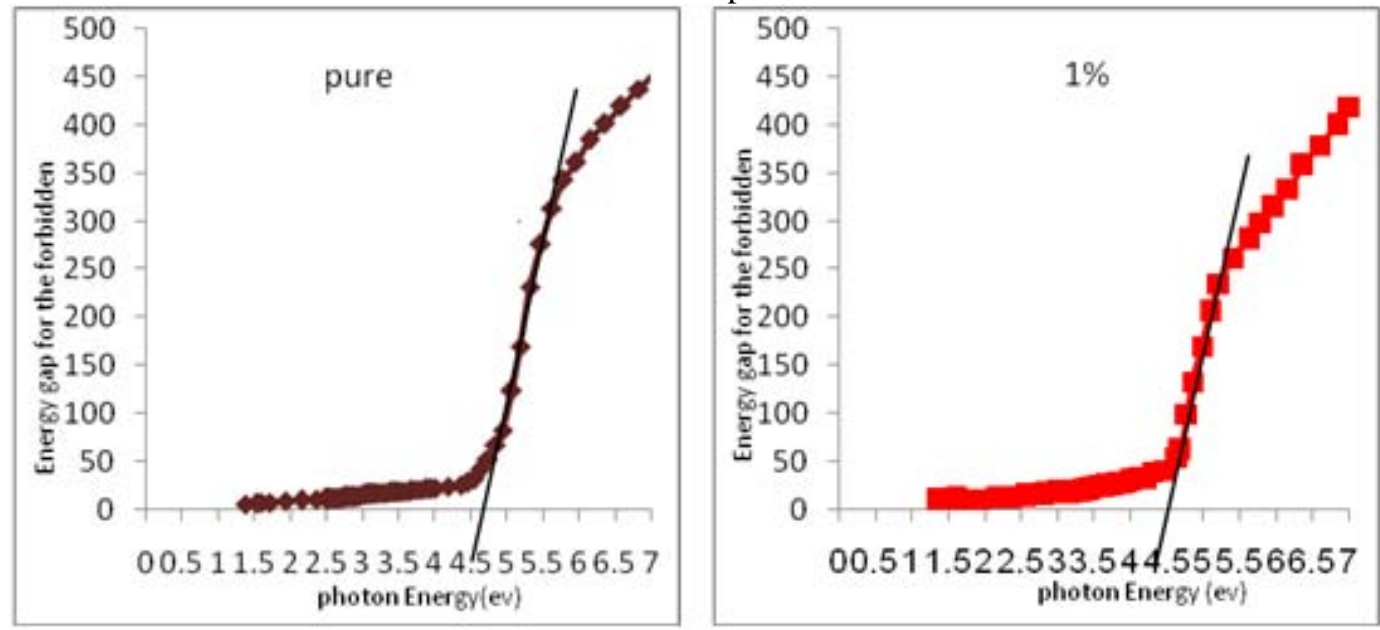

Volume 5 Issue 3, March 2016

www.ijsr.net 


\section{International Journal of Science and Research (IJSR) \\ ISSN (Online): 2319-7064}

Index Copernicus Value (2013): 6.14 | Impact Factor (2014): 5.611
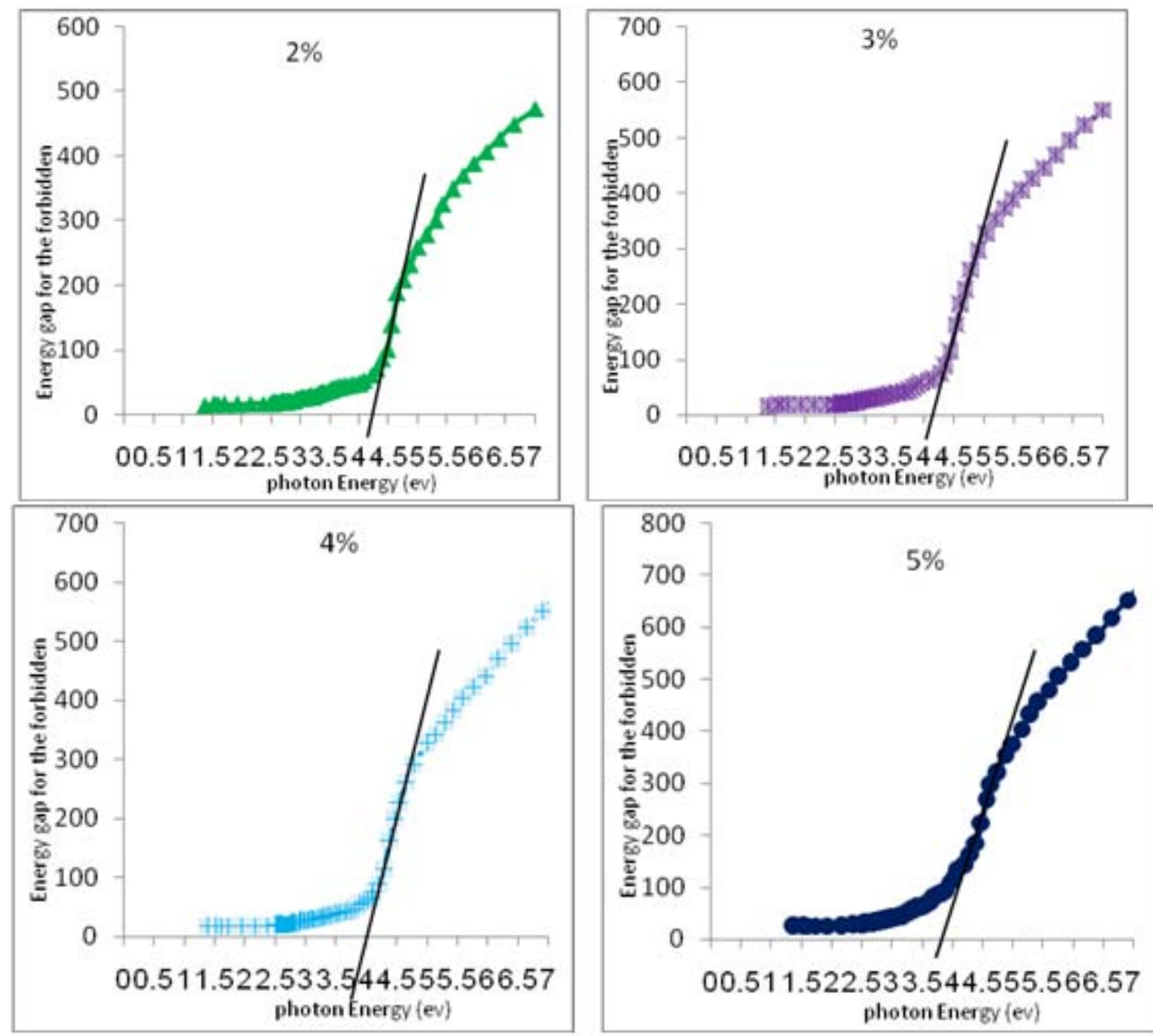

Figure 9: The energy gap for the forbidden indirect transition as a function of photon energy of (PVA-PVP-Ag) nanocomposites

\section{2- Atomic Force Microscope (AFM):}

Figures $(10,11,12,13,14,15)$ show structures of samples in two and three dimensions. All the images show homogeneous distribution with columnar structure.

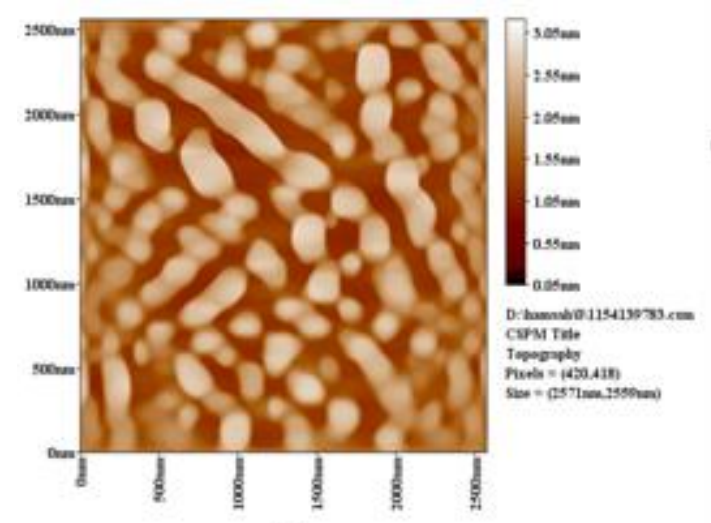

(a)
The average diameters, root mean square (RMS) and average roughness of the films are listed in Table (2). It was observed that the diameter of all samples is about the range of nanoscale Also it was shown very smooth surface with small roughness, smoothing of the films is possibly due to order of surface atoms to attain lower energy state.

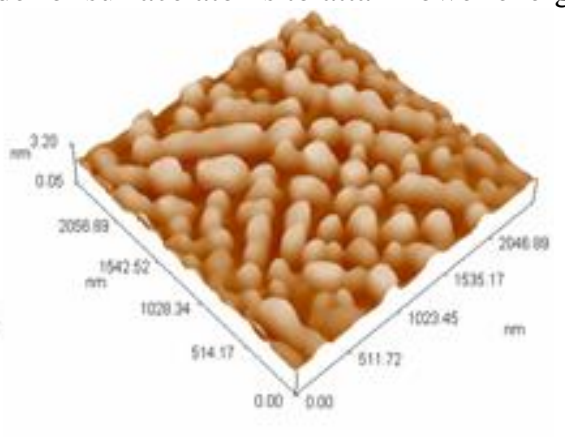

(b)

Figure 10: AFM images for pure sample (a) two dimensional (b) three dimensional 
International Journal of Science and Research (IJSR)

ISSN (Online): 2319-7064

Index Copernicus Value (2013): 6.14 | Impact Factor (2014): 5.611

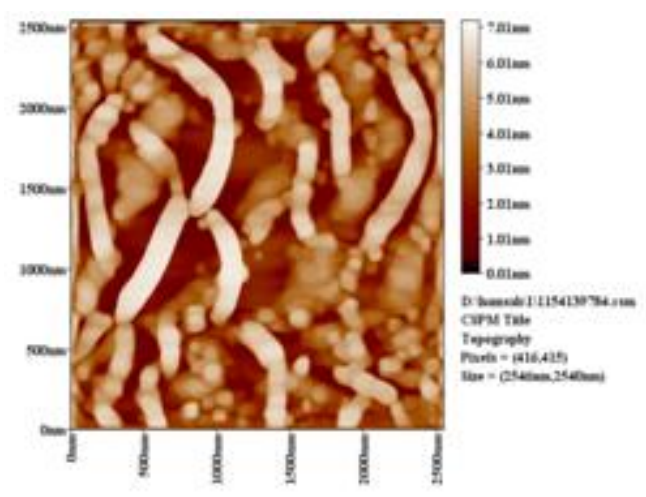

(a)

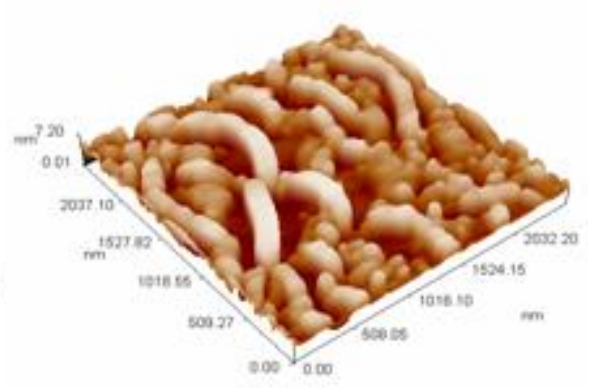

(b)

Figure 11: AFM images for sample 1\% (a) two dimensional (b) three dimensional,

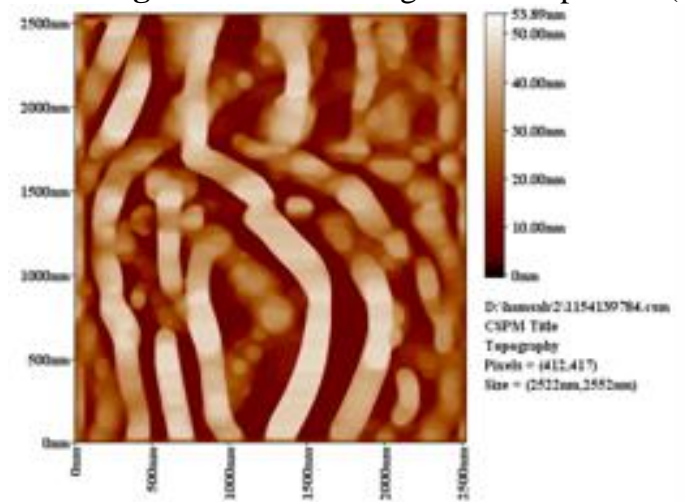

(a)

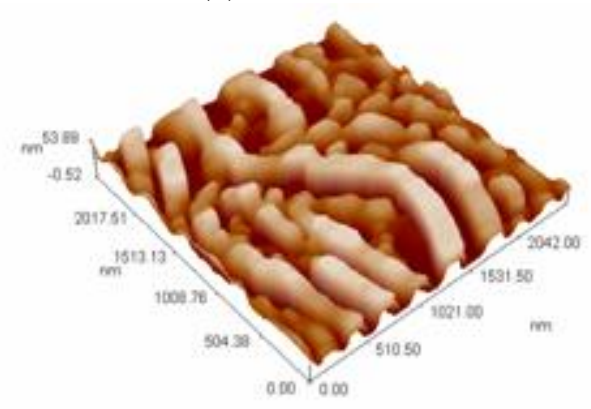

(b)

Figure 12: AFM images for sample 2\% (a) two dimensional (b) three dimensional,

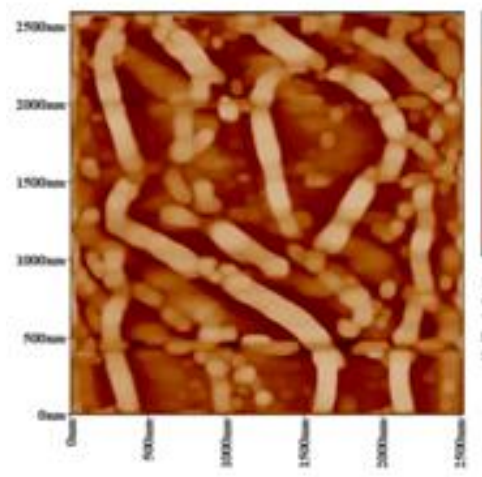

(a)

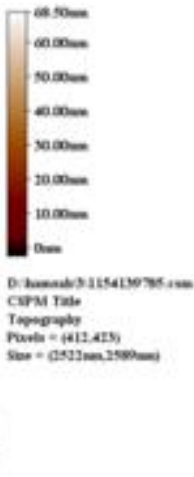

cind $n$

Timopits

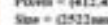

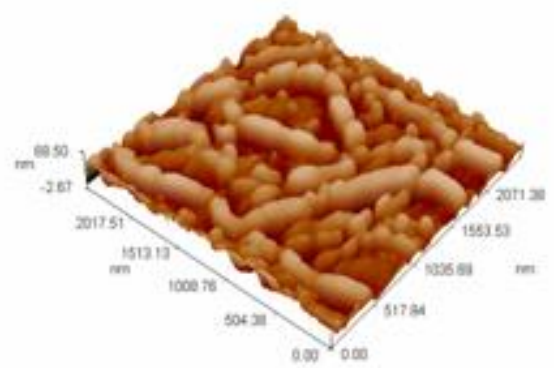

(b)

Figure 13: AFM images for sample 3\% (a) two dimensional (b) three dimensional,

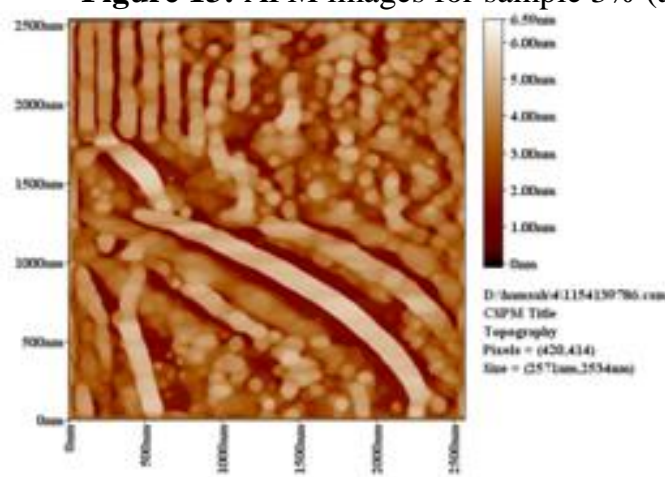

(a)

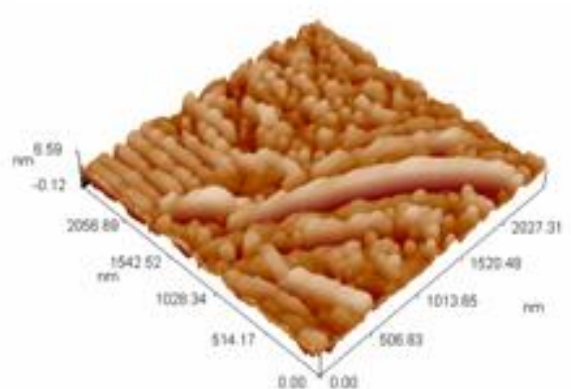

(b)

Figure 14: AFM images for sample 4\% (a) two dimensional (b) three dimensional 


\section{International Journal of Science and Research (IJSR) \\ ISSN (Online): 2319-7064}

Index Copernicus Value (2013): 6.14 | Impact Factor (2014): 5.611

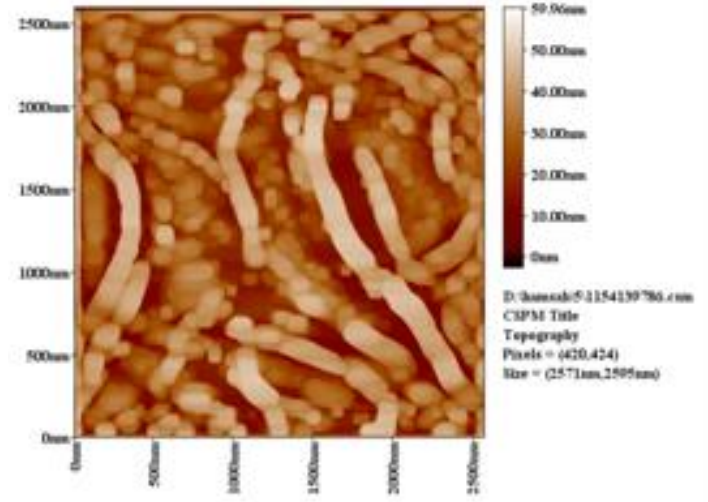

(a)

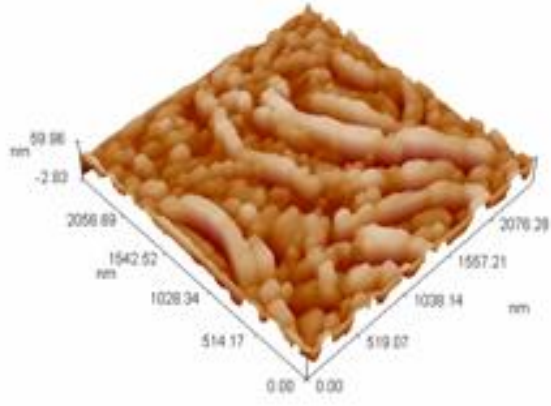

(b)

Figure 15: AFM images for sample 5\% (a) two dimensional (b) three dimensional

Table 2: Values (RMS) and (RS) and (Avg.Di) for samples

\begin{tabular}{|c|c|c|c|}
\hline Ag wt\% & $R M S(n m)$ & Roughness $(\mathrm{nm})$ & $D_{\text {ave }}(\mathrm{nm})$ \\
\hline 0 & 0.48 & 0.42 & 179.34 \\
\hline 1 & 1.62 & 1.42 & 104.53 \\
\hline 2 & 1.3 & 1.4 & 103.56 \\
\hline 3 & 1.38 & 1.8 & 97.07 \\
\hline 4 & 1.01 & 0.93 & 83.61 \\
\hline 5 & 0.72 & 0.44 & 89.41 \\
\hline
\end{tabular}

\section{3-The Optical Microscope}

The following figure (16) show the optical micrograph of (PVA-PVP-Ag) nanocomposite. The first film pure (PVAPVP) tend to white color, this is a color of the polymer (PVA and PVP) then increase the proportion of Ag (1\% , 2\% , 3\% , 4\% and 5\%) the color of films tend to be dark (nearly black) which reflect the metallic nature of $\mathrm{Ag}$, then it look dark black at $5 \%$.

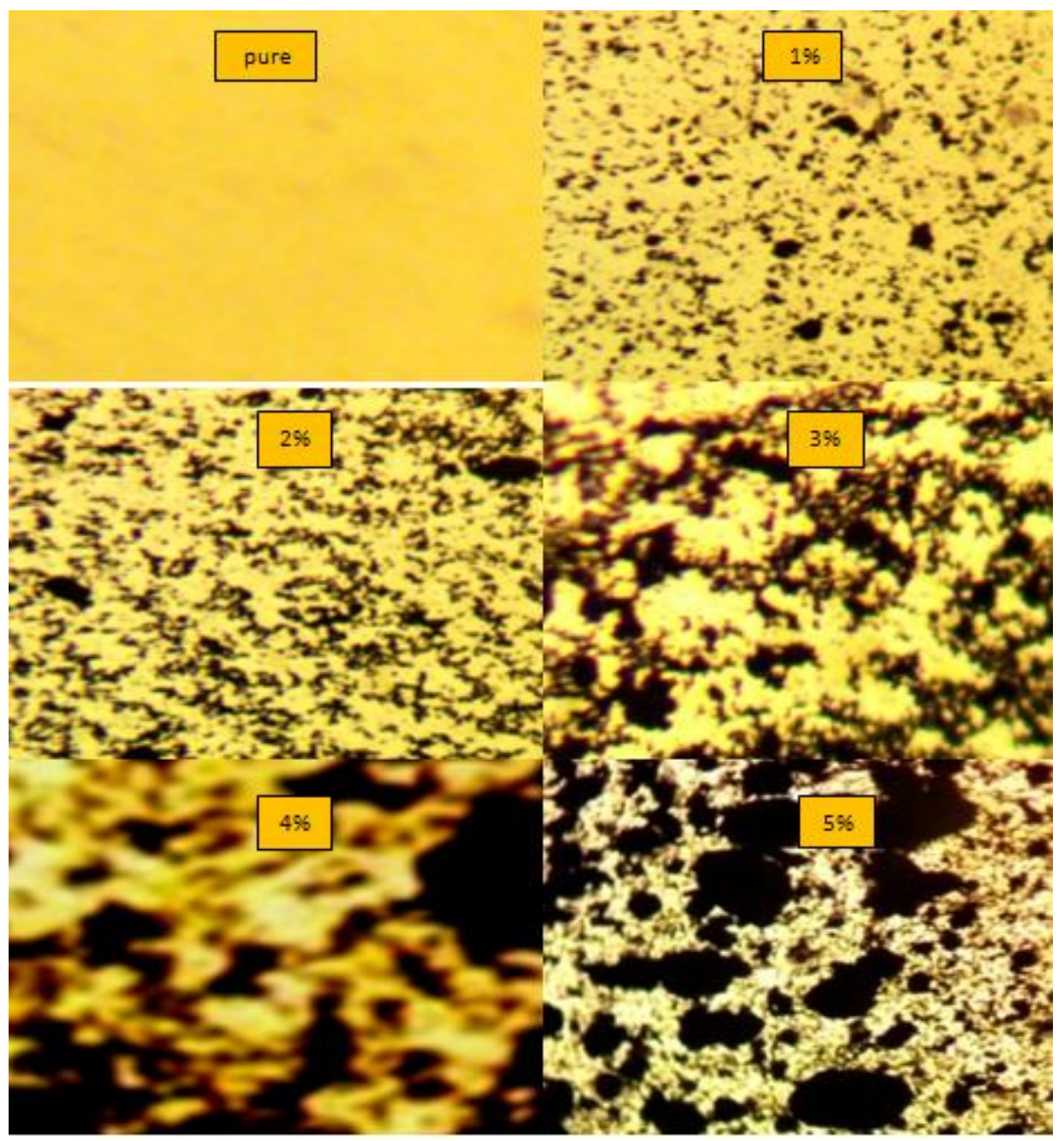

Figure 16: Photo micrographs power (X 400) 


\section{Conclusions}

1) The Electronic Transitions is indirect transitions.

2) Optical energy gap decreases with increasing Ag nanoparticles concentration.

3) The result of Optical Microscope show homogeneous distribution from (PVA-PVP-Ag).

4) The result of Atomic Force Microscope (AFM) show very smooth surface and small roughness.

\section{References}

[1] N.A. Che Lah and M.R. Johan: Int. J. Mater. Res. Vol. 102, pp.340-347, (2011).

[2] Wael H. Eisa , Yasser K. Abdel-Moneam, A.A. Shabaka, and Abd ElHameed M. Hosam,"In Situ Approach Induced Growth of Highly Monodispersed Ag Nanoparticles within Free Standing PVA/PVP Films",Spectrochimica Acta Part A: Molecular and Biomolecular Spect-roscopy, Vol. 95 , pp. 341-346 , 2012).

[3] V.V. Vodrik, J.V. Vukoric and J.M. Nedeljkovic: Colloid Polymer Sci, Vol. 287, pp.847-851, (2009).

[4] A. Munaim, H. A, " Electronic Transition for PS-LiF Composites" 6th Science Conference of Science College University of Mustansiriah, (2010).

[5] Z.H.Esfahani, M.Ghanipour and D.Dorranian "Effect of dye concentration on the optical properties of red-BS dyedoped PVA film" J Theor App Phys, (2014).

[6] M.H. AL-humairi ," Study the Optical and Electrical Properties of (PVA-Ag) and (PVATiO2)Nanocomposites", M.Sc. Thesis, University of Babylon, College of Education for Pure Sciences,(2013).

[7] Caixia Kan , ChangshunWang , JiejunZhu , and HongchenLi , "Formation of Gold and Silver Nanostructures within Polyvinylpyrollidone (PVP) Gel" ,J. of Solid State Chemistry, ( 2010).

[8] Mahshad Ghanipour ,and Davoud Dorranian ," Effect of Ag-Nanoparticles Doped in Polyvinyl Alcohol on the Structural and Optical Properties of PVA Films", J. of Nanomaterials, Article ID 897043,pp.1-10,(2013).

[9] S. Hadi, A. Hashim and A. Jewad „Optical properties of (PVA-LiF) Composites,, "Australian Journal of Basic and Applied Sciences", pp.2192-2195, ISSN 1991-8178, 5-9-( 2011).

[10] S. Kramadhati and K.Thyagarajan "Optical Properties of Pure and Doped (Kno3 and Mgc12)Polyvinyl Alcohol Polymer Thin Films" International Journal of Engineering Research and Development,(2013).

[11]R. A. Abed Jassim,"Effect of Chloride Groups (CoCl2, $\mathrm{CrCl} 2$ and $\mathrm{MnCl} 2)$ on the Electrical and Optical Properties for (PVA-PVP) Films", M.Sc. Thesis, . University of Babylon, College of Education for Pure Sciences,(2013).

[12] A. Wasan, T. Mohammed, and K. Tagreed, "The MR affect on optical properties for poly (Vinyl alcohol) films," Journal of Baghdad for Science, Vol. 8, No. 2, pp. 543-550,(2011).

[13]R. M. Ahmed, "Optical study on polymethylmethacrylate/ poly(vinyl acetate) blends," International Journal of Photoenergy, Vol. 2009, Article ID 150389, 7 pages, ( 2009). 